\title{
Effect of temperature and phonons on the spectral properties of a multi-level semiconductor quantum dot single-photon source
}

Nielsen, Per Kær; Nielsen, Torben Roland; Lodahl, Peter; Mørk, Jesper

Published in:

European Conference on Lasers and Electro-Optics 2009 and the European Quantum Electronics Conference. CLEO Europe - EQEC 2009

Link to article, DOI:

10.1109/CLEOE-EQEC.2009.5192439

Publication date:

2009

Document Version

Publisher's PDF, also known as Version of record

Link back to DTU Orbit

Citation (APA):

Nielsen, P. K., Nielsen, T. R., Lodahl, P., \& Mørk, J. (2009). Effect of temperature and phonons on the spectral properties of a multi-level semiconductor quantum dot single-photon source. In European Conference on Lasers and Electro-Optics 2009 and the European Quantum Electronics Conference. CLEO Europe - EQEC 2009 IEEE. https://doi.org/10.1109/CLEOE-EQEC.2009.5192439

\section{General rights}

Copyright and moral rights for the publications made accessible in the public portal are retained by the authors and/or other copyright owners and it is a condition of accessing publications that users recognise and abide by the legal requirements associated with these rights.

- Users may download and print one copy of any publication from the public portal for the purpose of private study or research.

- You may not further distribute the material or use it for any profit-making activity or commercial gain

- You may freely distribute the URL identifying the publication in the public portal 


\title{
Effect of temperature and phonons on the spectral properties of a multi-level semiconductor quantum dot single-photon source
}

\author{
P. Kaer, T.R. Nielsen, P. Lodahl, J. Mork \\ DTU Fotonik - Dept. of Photonics Engineering, Technical University of Denmark, DK-2800 Kgs. Lyngby, Denmark \\ Email: pkni@fotonik.dtu.dk
}

Since it was realized that efficient quantum computing can be performed using single photons and standard linear optics elements [1], immense international research activity has been aimed at developing semiconductor quantum dot (QD) single-photon sources (SPS). In order to optimise the design of SPS for high efficiency as well as increase the understanding of the physics, advanced and accurate models are needed that describes the complex solid-state environment the SPS is part of.

Here we describe a many-body model of a SPS based on the non-equilibrium Green's function formalism (NEGF), where the most important many-body interactions occurring in a semiconductor, namely the electronphonon, electron-photon, and electron-electron interaction are included. The novel part of the model is that we include both longitudinal optical (LO) and acoustical (LA) phonons in the NEGF model, which allows us to study complicated multi-level QDs, not possible within the commonly used independent boson model (IBM) [2]. Furthermore, avoiding the IBM we can study the interaction with photons on a fully quantum mechanical level, without having to resort to semiclassical approximations [3] or neglect initial correlations [4] as done in standard density matrix approaches. The main approximation imposed here is to restrict all self-energies to the selfconsistent Hartree-Fock level, which is allowed for relatively weak coupling constants.
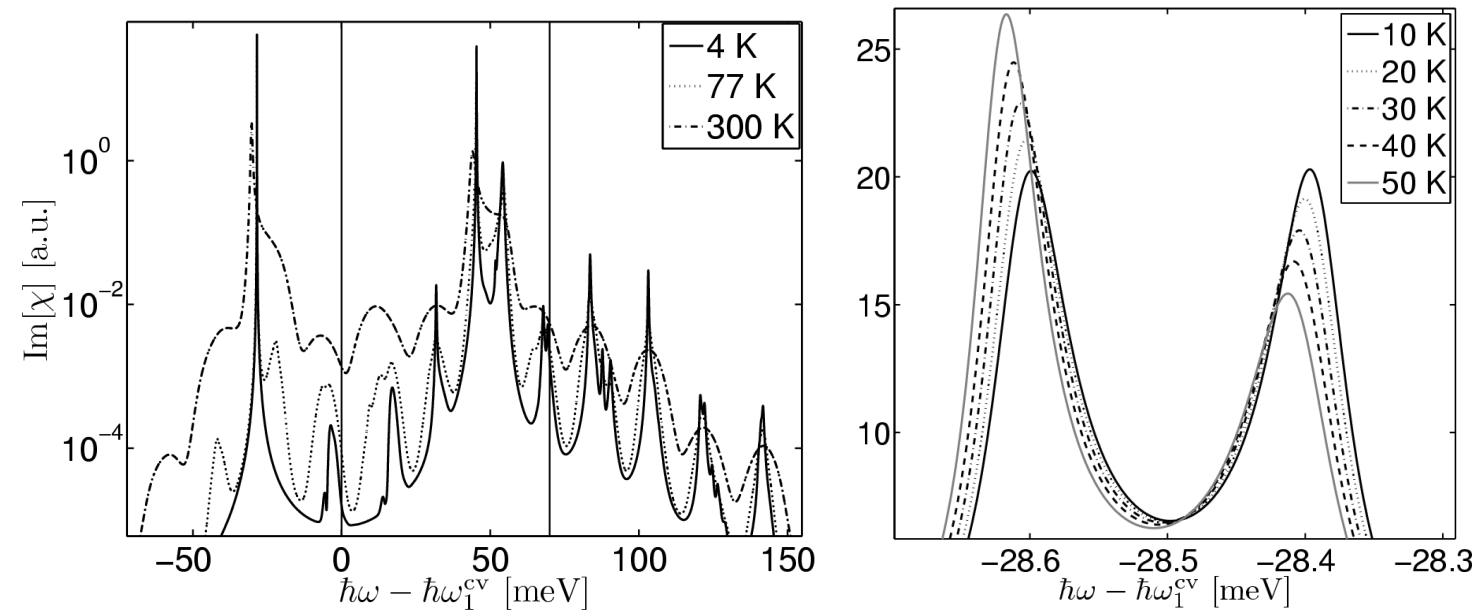

Fig. 1 Left: Absorption spectra of (left) a six-level QD at three temperatures showing the effect of the phonons as well as the Coulomb interaction. Right: The temperature dependence of the vacuum Rabi splitting induced by the presence of a resonant nanocavity, with a coupling strength of $0.1 \mathrm{meV}$ and a lifetime of $10 \mathrm{ps}$. Other paramaters are typical for a GaAs system.

As an application of the model we have calculated the linear absorption spectra of a QD with an s-shell and a double degenerate $\mathrm{p}$-shell (for both electrons and holes), interacting with LO and LA phonons as well as photons in a nanocavity. This multi-level QD model is more realistic than the usual simplistic two-level approximation often employed in the literature [2-4]. In Fig. 1 (Left) we show the full QD absorption spectrum at three temperatures spanning a relevant range for many experiments, and with the photon coupling set to zero. It is clearly seen that the free energy transitions, indicated by the vertical lines, have been renormalized due to the presence of the many-body interactions. A very rich structure of phonon assisted transitions is also visible, owing to the monochromatic nature of the LO phonons, and increasing temperature has the expected effect of broadening all peaks. In Fig. 1 (Right) we have included a nanocavity tuned to the renormalized s-transition and show how the vacuum Rabi splitting revealed in the absorption spectrum is affected by temperature. This is a relevant situation to model as many experiments use temperature to tune the SPS, and features such as the relative peak heights are measurable quantities and extractable from our model enabling a direct comparison. Models including the effects of temperature through phonons, are much needed in the rapidly evolving field of semiconductor cavity QED, and this model provides a first step towards being able to model realistic structures.

\section{References}

[1] E. Knill, R. Laflamme, and G. Milburn, Nature. 409, 46 (2001).

[2] B. Krummheuer, V. M. Axt, and T. Kuhn, Phys. Rev. B 65, 195313 (2002).

[3] F. Milde, A. Knorr, and S. Hughes, Phys. Rev. B 78, 035330 (2008).

[4] I. Wilson-Rae and A. Imamoglu, Phys. Rev. B 65, 235311 (2002). 